\title{
Ultrastructural validation of an improved culture system for boar efferent duct epithelium
}

\author{
B. M. Heiniger, M. H. Stoffel ${ }^{*}$ and A. E. Friess \\ Department of Veterinary Anatomy, University of Berne Veterinary School, CH-3001 Bern, Switzerland
}

\begin{abstract}
A tissue culture system in which cells retain defined ultrastructural and functional characteristics was established to provide a basis for functional investigations of the efferent ductules in boars. A currently used culture protocol for rat epididymal epithelium was used as a starting point and was subsequently modified because of unsatisfactory results. Epithelial plaques were isolated by mechanical uncoiling of the ductules and two sequential enzymatic digestion steps. Plaques were seeded onto extracellular matrix-coated permeable membranes and maintained in a two-chamber system. Samples taken before seeding and after 7 days in culture were processed for transmission and scanning electron microscopy. Perfusion-fixed material from earlier studies served as a reference to assess ultrastructural preservation. In addition, endocytotic activity was investigated by adding cationized ferritin to the culture medium on day 8 before fixation. At the end of the disaggregation procedure, cells were cuboidal, while cilia, microvilli and cell organelles were well preserved. After 7 days in culture, three types of cell formation were observed: cysts, pseudotubules and epithelial sheets. Cell sheets were made up of closely juxtaposed cells bearing motile kinocilia and exhibiting well-developed polar differentiation, as judged from the localization of cell junctions and organelles. Although it did not return to the values of native material, cell height was greater than that of cells grown according to the pre-existing protocol. Furthermore, preferential uptake of ferritin by principal cells after 7 days in culture was demonstrated. Preservation of these fundamental characteristics of the in vivo state corroborates that our in vitro system will furnish reliable information.
\end{abstract}

\section{Introduction}

Cell culture is a powerful tool for the study of cell functions, metabolic activities and their regulation (Freshney, 1987, 1992). Consequently, important insights into the process of sperm maturation have come from in vitro studies conducted on human and rat epididymal tissue (Tézon and Blaquier, 1981; Brown and Amann, 1984; Cooper et al., 1989; Klinefelter et al. 1992; Moore et al., 1992; Wong et al., 1992; Huang et al., 1994). Moreover, cell culture systems may be the only possible approach in animals too large for specific in vivo experiments, such as autoradiographic studies. Yet few reports on cell culture of epididymal epithelia from domestic mammals are available (Wagley et al., 1984; Joshi, 1985). This prompted us to develop a culture system for boar efferent duct epithelial fragments in view of intended studies on functional aspects of sperm maturation in this species.

The most recent protocols for the culture of epididymal tissue of laboratory rodents and humans have used epithelial cell aggregates generally obtained from the epididymal duct (Cooper et al., 1989; Byers et al., 1992; Klinefelter et al., 1992; Moore et al., 1992) and, in a few instances, from the efferent

*Correspondence.

Received 24 July 1995 ductules (Byers et al, 1985a; Raczek et al., 1992). Epithelial fragments are prepared by microdissection and enzymatic digestion of tubule segments. These epithelial plaques are seeded onto the extracellular matrix-coated permeable membrane of commercially available inserts. Immersion of these inner chambers in larger wells yields a two chamber system with basically separate basal and luminal compartments. This is the best approach so far to maintain some degree of histotypic organization and polar differentiation of epithelial cells in culture. However, all tissue culture systems have inherent limitations, and extrapolation of results from in vitro studies to the in vivo state requires careful assessment of structural and functional integrity. To validate our in vitro system, we examined its ability to preserve native ultrastructural characteristics. In addition, we wanted to procure evidence of a known vectorial function. Therefore, ultrastructure of cells before seeding and after 7 days in culture was systematically compared with perfusion-fixed tissue (Stoffel et al., 1991; Stoffel and Friess, 1994) and endocytotic activity was corroborated by means of ferritin uptake.

Protocols currently used for rat epididymal epithelium (Klinefelter et al., 1992) yielded unsatisfactory results with respect to morphological preservation of boar efferent duct cells in vitro. Therefore, we carefully optimized the disaggregation steps, composition of both culture media and 
extracellular matrix, and plating density until our ultrastructural and functional demands were fulfilled. The protocol presented here provides close approximation of native structural and functional properties after 7 days in culture and thus is suited to yield relevant and reliable information.

\section{Materials and Methods}

\section{Animals}

Epididymides from mature large white boars, Sus scrofa f. dom. (approximately $110 \mathrm{~kg}$ body mass), were obtained at castration.

\section{Culture media}

Modified Hank's balanced salt solution (HBSS; $100 \mathrm{ml}$; Sigma, St Louis, MO) was supplemented as follows: $0.20 \mathrm{~g}$ BSA (Sigma); $0.42 \mathrm{~g}$ Hepes (Sigma); $0.09 \mathrm{~g}$ D-glucose (Sigma); $2.5 \mathrm{mg}$ soybean trypsin inhibitor (STI; Sigma); $1.0 \mathrm{ml}$ MEMsodium pyruvate $100 \mathrm{mmol} \mathrm{l}^{-1}$ (Gibco, New York, NY), $\mathrm{pH} 7.4$.

Minimum Essential Medium (MEM) Earles Salts D-Val $(500 \mathrm{ml}$; Gibco) was supplemented as follows: $5.0 \mathrm{ml}$ MEMsodium pyruvate $100 \mathrm{mmol} \mathrm{l}^{-\mathrm{I}}$ (Gibco); $5.0 \mathrm{ml}$ MEM-nonessential-amino-acids $100 \times$ (Gibco); $292 \mathrm{mg}$ L-glutamin $100 \times$ (Gibco); $0.5 \mathrm{~g} \mathrm{BSA}$; $0.1 \mathrm{~g}$ L-carnitine (Sigma); $2.5 \mathrm{ml}$ gentamycin sulfate (Sigma); $2.5 \mathrm{mg}$ transferrin (Sigma); $2.5 \mathrm{mg}$ insulin (Sigma); $0.18 \mathrm{mg}$ hydrocortisone (Sigma); $0.14 \mathrm{mg}$ testosterone (Fluka, Buchs); $0.15 \mathrm{mg}$ dihydrotestosterone (Fluka); $50 \mu \mathrm{g}$ retinol acetate (Sigma); $2.503 \mathrm{~g}$ Hepes (Sigma). Ten per cent (v/v) fetal calf serum (FCS; Biological Industries, Bet Haemek, Israel) was added and the medium was adjusted to $\mathrm{pH} 7.4$.

All media were filter sterilized (Stericups GV5 from Millipore, Bedford, MA).

\section{Extracellular matrix, cell substrate and culture plates}

Inserts, $12 \mathrm{~mm}$ in diameter (Millipore Millicell CM PICM01250) were used as inner chambers. Before use, the permeable membranes were coated with $50 \mu \mathrm{l} \mathrm{cm} \mathrm{cm}^{-2}$ of a commercially available extracellular matrix (Basement Membrane Matrige ${ }^{([i m}$ from Becton Dickinson, Bedford, MA) diluted 1:7 with supplemented MEM (Byers et al., 1992). Coated inserts were placed in 12-well cell culture clusters (Costar, Cambridge, MA) and dried for $30 \mathrm{~min}$ in an incubator at $34^{\circ} \mathrm{C}$.

\section{Disaggregation and culture of epithelial fragments}

The following disaggregation and culture procedures were modified from protocols published by Byers et al. (1985b) and Klinefelter et al. (1992).

Immediately after castration, the head of each epididymis was transferred to sterile HBSS and the efferent ducts were carefully uncoiled with microsurgical instruments. A stereomicroscope was used for visual control to avoid damage to the tubules and the HBSS was changed several times. Uncoiled ductules were cut into fragments of $5-10 \mathrm{~mm}$, transferred to supplemented HBSS containing $300 \mathrm{U}$ collagenase $\mathrm{ml}^{-1}$ (Worthington, Freehold, NJ), and incubated in a water bath at $34^{\circ} \mathrm{C}$ with a shaker set at 120 cycles $\min ^{-1}$. Digestion was discontinued as soon as fragments appeared as fine, transparent tubules, after $60-75 \mathrm{~min}$. After vigorous pipetting of the sediment, tubule fragments were allowed to settle. The supernatant was discarded and the pellet was resuspended and pipetted with supplemented MEM containing $150 \mathrm{U}$ collagenase $\mathrm{ml}^{-1}$. After $30 \mathrm{~min}$, the size of the cell plaques was assessed every $10 \mathrm{~min}$ under a microscope and disaggregation was stopped as soon as fragments had reached $200-400 \mu \mathrm{m}$ in diameter. Before seeding, a semi-quantitative approach (Raczek et al., 1992) was used to calibrate the number of cell plaques per insert. A pellet volume of $0.0125 \mathrm{ml}$, diluted in $0.5 \mathrm{ml}$ supplemented MEM, was used per insert and this resulted in optimal cell density. Fluid level was brought to $5 \mathrm{~mm}$ by adding $1.9 \mathrm{ml}$ supplemented MEM to the outer chamber. Medium was changed after the first $24 \mathrm{~h}$ and then every $48 \mathrm{~h}$. Ciliary beat, and attachment and spreading of the epithelial sheets were surveyed daily by light microscopy. The extent of the surface covered by viable cells was determined by performing a vital staining with $0.1 \%(\mathrm{w} / \mathrm{v})$ acridine orange in supplemented HBSS on day 8. Epifluorescence (excitation: pass band filter $450-490 \mathrm{~nm}$; emission: long wave pass band filter $520 \mathrm{~nm}$ ) and transillumination micrographs (Zeiss Axiophot) of identical areas were compared and estimates of covered and uncovered surface areas were determined by use of an overlay grid.

\section{Ferritin uptake}

After 7 days in culture, media were removed from both chambers. After emptying the outer chamber, medium from the inner chamber was allowed to drain through the permeable membrane for $30 \mathrm{~min}$. If required, remaining medium was drawn off carefully. Grown cells were gently washed with supplemented HBSS. Supplemented HBSS containing $5 \mathrm{mg}$ cationized ferritin $\mathrm{ml}^{-1}$ (Sigma) was then added. After incubation for $10 \mathrm{~min}$ at $34^{\circ} \mathrm{C}$, inserts were again washed as above and cells were fixed immediately (see below).

\section{Fixation and processing for electron microscopy}

Cells were fixed by immersion in diluted Karnovsky's fixative $(1 \%(\mathrm{w} / \mathrm{v})$ paraformaldehyde, $1.25 \%(\mathrm{v} / \mathrm{v})$ glutaraldehyde in 0.1 mol cacodylate buffer $\mathrm{I}^{-1}$ with $2 \mathrm{mmol} \mathrm{CaCl} \mathrm{I}^{-1}$; $\left.\mathrm{pH} \mathrm{7.4;} 4^{\circ} \mathrm{C} ; 1 \mathrm{~h}\right)$. Tissue was then postfixed with $1 \%(\mathrm{w} / \mathrm{v})$ $\mathrm{OsO}_{4}$ in cacodylate buffer for $1 \mathrm{~h}$ at $4^{\circ} \mathrm{C}$, dehydrated through an ascending ethanol series, and embedded for transmission electron microscopy (TEM) in an Epon-Araldite mixture according to standard protocols. Sections were stained with uranyl acetate and lead citrate and examined in a Zeiss EM 109. After dehydration, samples selected for scanning electron microscopy (SEM) were critical point dried (Balzers CPD 030), mounted on stubs with conducting carbon, sputter-coated with $20 \mathrm{~nm}$ of gold (Balzers SCD 004) and examined in a Philips PSEM 500 scanning electron microscope. 

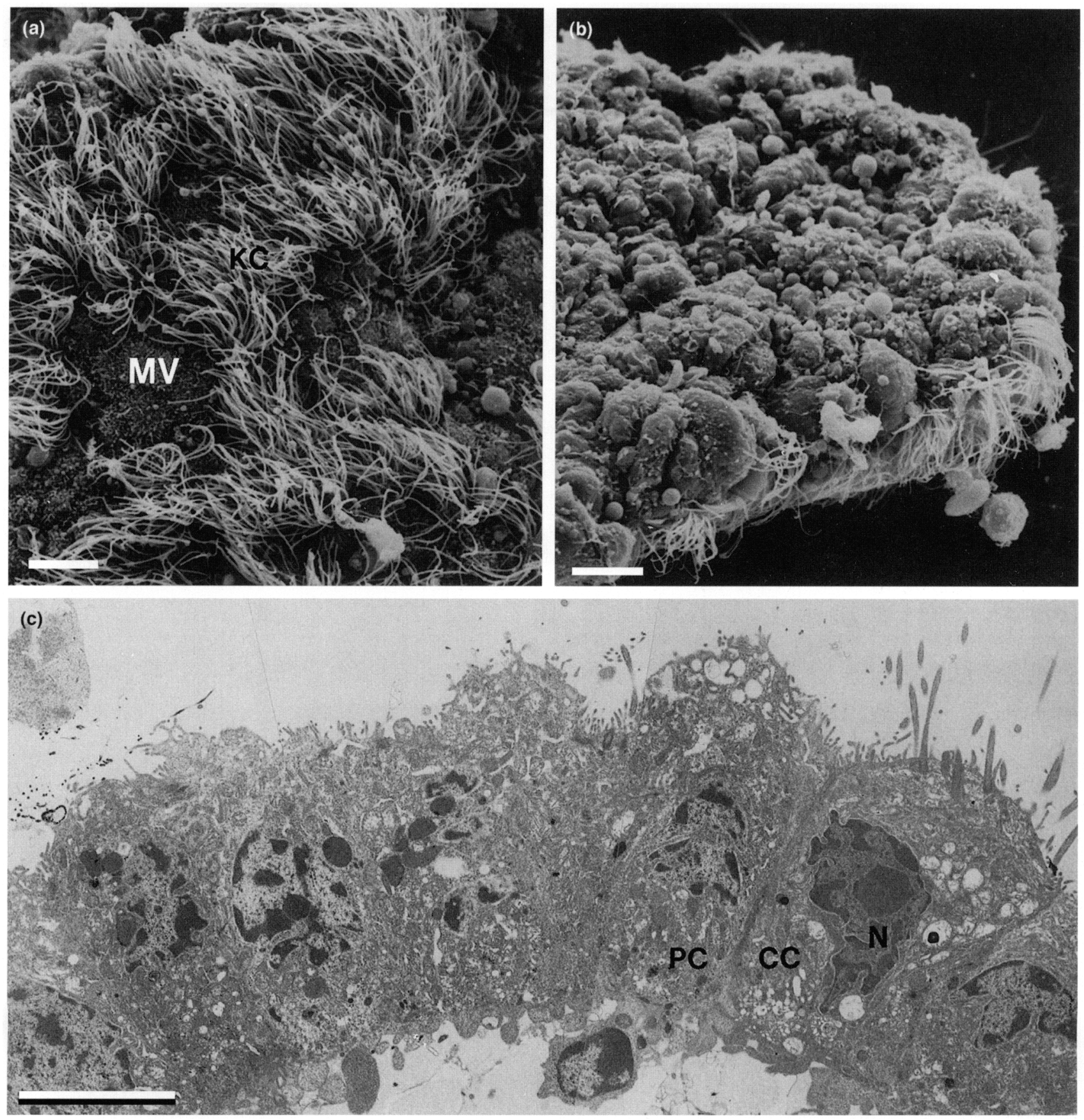

Fig. 1. Cell plaques prior to seeding: (a) scanning electron micrograph of the apical side, exhibiting well preserved microvilli (MV) and kinocilia $(\mathrm{KC})$; (b) scanning ciectron micrograph of the basal side, showing that epithelial cells are freed of peritubular elements (c) transmission electron micrograph showing principal cells (PC) and ciliated cells (CC) as well as indentations of nuclear membranes ( $\mathrm{r}$ ) Scale bars represent $5 \mu \mathrm{m}$.

\section{Results}

Morphology of cell platites

The disaggregation protocol yielded epithelial plaques of about $200-400 \mu \mathrm{m}$ in diameter and some single cells. Breakdown of efferent ductules was complete since tubular structures were never observed in samples collected before seeding. Examination of cell plaques fixed at the end of the disaggregation protocol (Fig. I) revealed a substantial decrease in cell height to approximately $25 \%$ of that of perfusion-fixed epithelium. Both principal and ciliated cells were cuboidal but still contained the normal complement of organelles. However, nuclear shape seemed less regular than in native tissue owing to indentations of the nuclear envelope. The apical plasma membrane was typical, the principal cells forming a cobblestone-like pattern which was interrupted by tufts of kinocilia. Examination of the basal side of the cell plaques revealed a complete absence of peritubular elements. 
(a)
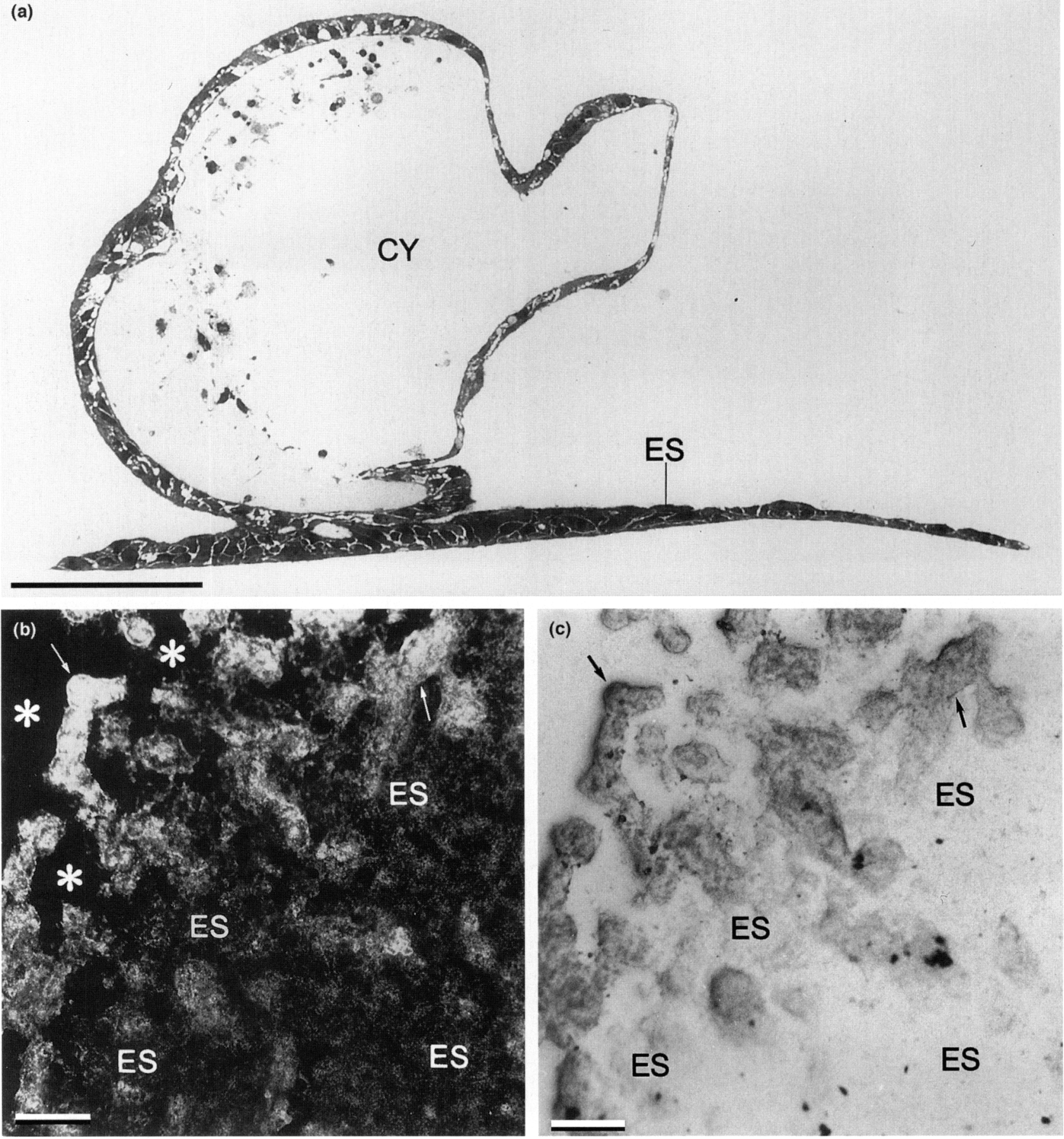

Fig. 2. Spreading of epithelial fragments: (a) semithin section through epithelial sheet (ES) with attached cyst (CY); (b) epifluorescence image of cultured tissue adhering to filter membrane on day 8 , vital staining with $0.1 \%$ acridine orange: fluorescence clearly reveals epithelial sheets (ES), three-dimensional formations (arrows), and a few bare filter membrane areas (asterisks); (c) transillumination micrograph of identical area as (b): though less distinctly, epithelial sheets (ES) and three-dimensional formations (arrows) can nonetheless be discerned. Scale bars represent $100 \mu \mathrm{m}$.

\section{Attachment and spreading of cell plaques}

Attachment of cell plaques to the extracellular matrix was complete after $24 \mathrm{~h}$ in culture. It was followed by outgrowth from the borders of the original fragments and by local three-dimensional reorganization of the cell aggregates (see below). About $65 \%$ of the surface area was occupied by epithelial sheets, while three-dimensional formations took up some $25 \%$ (Fig. 2). By day 8 , filter membranes were, therefore, covered to approximately $90 \%$, that is, confluence was not complete. No evidence of mitosis was detected by either light or transmission electron microscopy. 

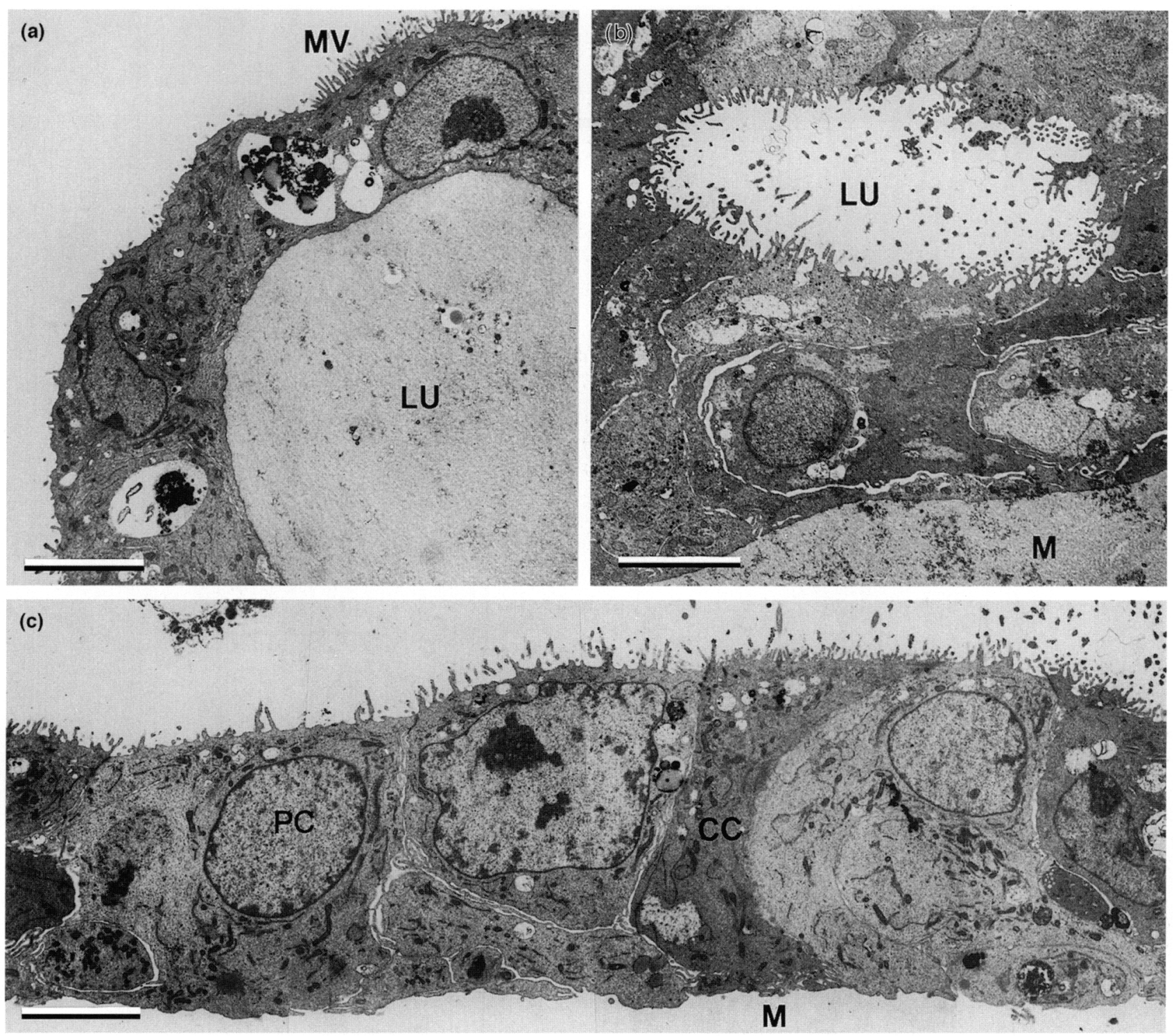

Fig. 3. Transmission electron micrographs revealing spatial organization of epithelial cells after 7 days in culture: (a) cyst: the large lumen (LU) is delimited by the basal side of the cells, while the apical side, bearing microvilli (MV), faces outwards; (b) pseudotubule; the lumen (LU) is bounded by the apical membrane of the cell, while the basal plasmalemma rests on the matrix-coated permeable support (M); (c) epithelial sheet made up polarized principal cells (PC) and ciliated cells (CC) which rest on the matrix-coated permeable membrane (M). Scale bars represent $5 \mu \mathrm{m}$.

\section{Types of cell aggregate}

After 7 days in culture, three types of cell aggregate could be distinguished (Figs 2a and 3). Three-dimensional formations were designated as cysts when the lumen enclosed was bounded by the basal plasmalemma (Figs 2a and 3a), and as pseudotubules when the lumen was delimited by the apical cell membranes (Fig. 3b). Hemicysts and tubule-like structures became apparent after 3 days in culture. Between cysts and pseudotubules, large areas were covered by polarized epithelial sheets resting on the extracellular matrix with their basal plasmalemma. While these sheets typically were made of monolayers, overlapping of epithelial cells in two or three layers was also encountered in some areas. Lateral plasma membranes were closely apposed over wide areas, whereas the apical plasmalemma bore microvilli and kinocilia, respectively. Cells were cuboidal and reached about $25-3.3 \%$ of the epithelial height of native tissue (Fig. 3c). They contained a typical complement of cell organelles. No ultrastructural evidence of other cell types (fibroblasts, smooth muscle cells) was found.

\section{Principal cells and ciliated cells in epithelial sheets}

Principal cells and ciliated cells are shown (Fig. 4). Plasmalemma was continuous in both cell types. Principal cells showed apical pits between well preserved microvilli, while 

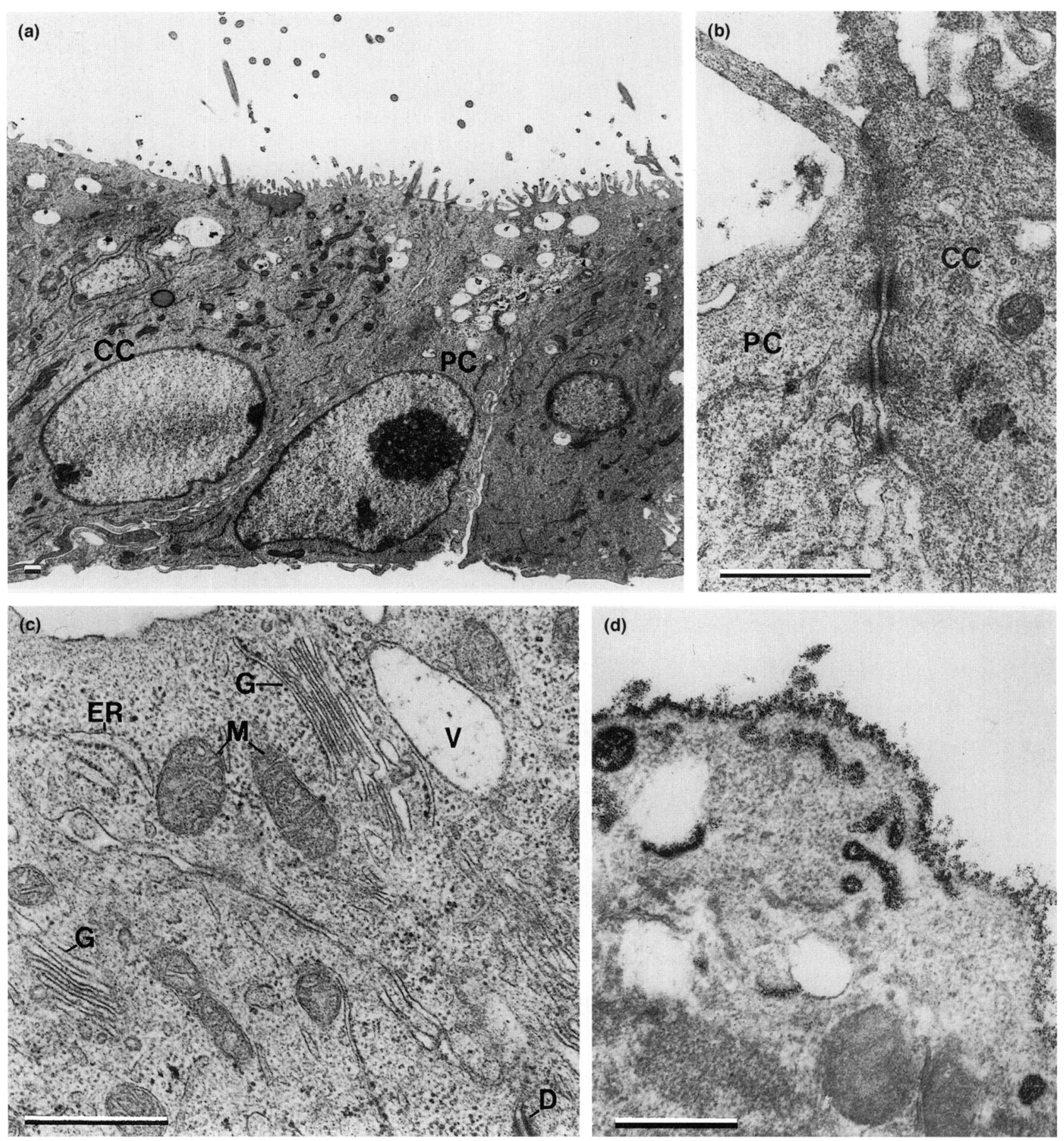

Fig. 4. Transmission electron micrographs of epithelial sheets after 7 days in culture: (a) principal cell (PC) containing numerous vesicles in apical region and ciliated cell (CC) with typical complement of organelles; (b) desmosomes connecting a principal (PC) and a ciliated cell (CC); (c) supranuclear region of adjacent principal cells showing a desmosome (D), well-preserved mitochondria (M), Golgi apparatus (G), endoplasmic reticulum (ER), and a large vesicle (V); (d) unstained section of a principal ceil with membrane-bound and endocytosed ferritin. Scale bars represent $0.5 \mu \mathrm{m}$.

ciliated cells exhibited microvilli and kinocilia. Lateral plasma membranes displayed elaborate interdigitations and were connected to neighbouring cells by desmosomes and tight junctions. Nuclei were oval with prominent nucleoli. Both outer and inner membranes of cristae-type mitochondria were intact. Cisternae of smooth and rough endoplasmic reticulum were distributed over the cytoplasm, while Golgi complexes were found in their typical supranuclear location. As in native tissue, Golgi complexes were conspicuous in principal cells but small in ciliated cells. Vesicles and lysosomes were particularly numerous in the apical cytoplasm of principal cells. Cytoskeletal elements were also detected. 


\section{Endocytosis}

Ferritin was preferentially bound and endocytosed by principal cells (Fig. 4d).

\section{Discussion}

Although in vitro systems have been widely used for the study of epididymal functions, only a limited number of reports have included detailed morphological data (Wagley et al., 1984; Byers et al., 1985a, b; Joshi, 1985; Cooper et al., 1989; Raczek et al., 1992). We consider ultrastructural validation of the culture system to be critical with respect to both the identification of the cell types present and to the status of polar differentiation, especially in highly specialized epithelia. Evidence of morphological resemblance between cultured and native cells is, therefore, a prerequisite to any conclusions inferring in vivo functions from in vitro experiments.

Vital staining of cultured cells on day 8 revealed that $10 \%$ of the filter membranes remained devoid of viable cells and that confluence, therefore, was not complete. However, beginning on day 2, cell plaques expanded on the filter membrane, thereby generating epithelial sheets which eventually covered $65 \%$ of the available surface area. Since no evidence of mitosis was ever found by light or electron microscopy, it must be assumed that spreading of epithelial sheets is due to a spatial reorganization of the cells brought into culture.

Ultrastructural observations in the study reported here show that fibrocytes were successfully precluded by careful design of the disaggregation steps and by excluding L-valine from the culture media (Gilbert and Migeon, 1975; Olson et al., 1983). The reduced epithelial height of cultured cells as compared with native tissue (Stoffel et al., 1991; Stoffel and Friess, 1994) remains a disturbing drawback. However, this is the first report to our knowledge that shows that epithelial plaques take on a more cuboidal appearance after disaggregation, that is before plating. Since the cells at the boundaries of the plaques were particularly low, it seems that the loss of tubular organization contributes to this alteration. The culture system itself, therefore, did not lead to this change but did fail to provide an environment in which cells would return to their original shape. Pseudotubules and cysts were also lined by cuboidal cells, casting some doubt on whether three-dimensional reorganization in culture helps in restoring columnar cell shape.

Despite this alteration in epithelial height, polar differentiation was maintained as shown by the proper orientation of the apical cell membrane as well as by the location of cellular junctions and organelles. In an earlier study (Stoffel and Friess, 1994), we interpreted interdigitations of the lateral plasma membrane within a slightly extended intercellular space as evidence of water transport through the epithelium. Adjacent cells in culture exhibit a very similar interlocking pattern of their plasmalemma. Taken together, these findings support the view that vectorial metabolic pathways are intact.

Besides morphological evidence of kinocilia, ciliary beat after 7 days in culture could still be observed by light microscopy.

Ferritin is a tracer for adsorptive endocytosis. Experiments in vivo revealed that ferritin binds almost exclusively to the apical plasma membrane of principal cells and that these cells are involved in its endocytosis (Stoffel and Friess, 1994). Demonstration of preferential uptake of ferritin by principal cells in vitro, therefore, is an indication that normal cellular activity was maintained after 7 days in culture.

To achieve satisfactory preservation of ultrastructural and functional characteristics of boar efferent duct epithelium in culture, protocols currently used for rat epididymal epithelia (Klinefelter et al., 1992) required some adjustments. These included ensuring an adequate and equal size of the plaques to be seeded $(200-400 \mu \mathrm{m})$, achieving an optimal cell concentration per insert by means of a semi-quantitative determination of the tissue volume used in culture, reducing the thickness of the extracellular matrix to about $\mathrm{I} \mu \mathrm{m}$ and modifying the composition of the culture media (major changes included lower concentrations of hydrocortisone, testosterone, and dihydrotestosterone, exclusion of L-valine, and the addition of retinoic acid).

Collectively, these results show that species and tissue differences must be taken into account when establishing an in vitro system and that refining culture parameters may lead to substantial improvements. Although further efforts are needed to attain the goal of full morphological congruity between native and cultured epithelium, we consider that boar efferent duct cells have adequately maintained their fundamental ultrastructural and functional characteristics in our culture system to make it trustworthy for functional investigations. We, therefore, expect this technique to be of value in the effort to unravel the sperm maturation process in this domestic species.

The authors are grateful to the Large Animal Clinics, division of swine diseases, for providing the material, to $\mathrm{C}$. Furer for her meticulous technical support and to $S$. König for his excellent photographic work. They also thank the Department of Veterinary Neurology for providing access to their cell culture laboratory.

\section{References}

Brown DV and Amann RP (1984) Inhibition of testosterone metabolism in cultured rat epididymal principal cells by dihydrotestosterone and progesterone Biology of Reproduction 30 67-73

Byers SW, Musto NA and Dym M (1985a) Culture of ciliated and nonciliated cells from rat ductuli efferentes Journal of Andrology 6 271-278

Byers SW, Djakiew D and Dym M (1985b) Structural features of rat epididymal epithelial cells in vitro Journal of Reproduction and Fertility 75 401-411

Byers SW, Citi S, Anderson JM and Hoxter B (1992) Polarized functions and permeability properties of rat epididymal epithelial cells in vitro Journal of Reproduction and Fertility 95 385-396

Cooper TG, Yeung CH and Meyer R (1989) Immature rat epididymal epithelial cells grown in static primary monolayer culture on permeable supports I. Vectorial secretion Cell and Tissue Research 256 567-572

Freshney RJ (1987) Culture of Animal Cells. A Manual of Basis Technique (2nd Edn). Alan R. Liss Inc., New York

Freshney RJ (1992) Animal Cell Culture: a Practical Approach (2nd edn). IRL Press, Oxford

Gilbert SF and Migeon BR (1975) D-Valine as a selective agent for normal human and rodent epithelial cells in culture Cell 5 11-17

Huang SJ, Chan $\mathrm{HC}$ and Wong PYD (1994) Adrenaline-regulated $\mathrm{Cl}^{-}$-transport in cultured single rat epididymal cells measured by an entrapped $\mathrm{Cl}^{-}$. sensitive fluorophore Journal of Physiology 474 183-191

Joshi MS (1985) Isolation and cell culture of epithelial cells of cauda epididymis of the bull Biology of Reproduction 33 187-200 
Klinefelter GR, Roberts NL and Suarez JD (1992) Direct effects of ethane dimethanesulfonate on epididymal function in adult rats Journal of Andrology 13 409-421

Moore HDM, Curry MR, Penfold LM and Pryor JP (1992) The culture of human epididymal epithelium and in vitro maturation of epididymal spermatozoa Fertility and Sterility $\mathbf{5 8} 776-783$

Olson GE, Jonas-Davies J, Hoffman LH and Orgebin-Crist MC (1983) Structural features of cultured epithelial cells from the adult rat epididymis Journal of Andrology 4 347-360

Raczek S, Yeung CH, Hertle L, Schulze H and Cooper TG (1992) Appearance and endocytotic activity of epithelial cells from human efferent ducts in primary monolayer culture Cell and Tissue Research 270 513-519

Stoffel MH and Friess AE (1994) Morphological characteristics of boar efferent ductules and epididymal duct Microscopy Research and Technique 29 411-431
Stoffel MH, Friess AE and Kohler T (1991) Efferent ductules of the boar - a morphological study Acta Anatomica 142 272-280

Tezón JG and Blaquier JA (1981) The organ culture of human epididymal tubules and their response to androgens Molecular and Cellular Endocrinology $21233-242$

Wagley LM, Versluis TD, Brown DV and Amann RP (1984) Culture of principal cells from the ram epididymis. A comparison of the morphology of principal cells in culture and in situ Journal of Andrology 5 389-408

Wong PYD, Huang SJ, Leung AYH, Fu WO, Chung YW, Zhou TS, Yip WWK and Chan WKL (1992) Physiology and pathophysiology of electrolyte transport in the epididymis. In Spermatogenesis-Fertilization-Contraception: Molecular, Cellular and Endocrine Events in Male Reproduction pp 319-344 Eds E. Nieschlag and UF Habenichts. Springer-Verlag, Heidelberg, Berlin 